54. Журнал XXV-го заседания от 19 июня 1900 г. // Отчет СГУАК за 1900 г. Симбирск, 1901. С. 44-48.

55. Покровский Ф.В. Археологическая карта Гродненской губернии. Вильна: Типография А.Г. Сыркина, 1895. 165 с.

56. Алабин П.В. Древности, найденные в Самарской губернии и хранящиеся в Самарском Публичном музее. Самара, 1895.19 с.

57. Алабин П.В. Нам известные остатки древности в Самарском крае // Труды IV Археологического Съезда в России, бывшего в Казани с 31 июля по 18 августа 1877 года. Казань, 1884. С. 1-7.

58. Решетов А.М. Александр Александрович Миллер - выдающийся археолог, этнограф и музеевед (к 125-летию со дня рождения) // Интеграция археологических и этнографических исследований. Нальчик; Омск: Изд-во ОмГПУ, 2001. С. 8-16.

59. Ососков П.А., Коростелев Н.А., Гаврилов Н.Г. Россия. Полное географическое описание нашего отечества: Настольная и дорожная книга для русских людей / под ред. В.П. Семенова. В 19-ти т. Т. 6:
Среднее и Нижнее Поволжье и Заволжье. Изд. А.Ф. Девриена. СПб., 1901. 599 с.

60. Даценко П.И., Прасолов Л.И. Материалы для оценки земель Самарской губернии. 2 т. Самара: Земская тип., 1903-1906.

61. Протопопов И.А. Список населенных мест Самарской губернии, составлен в 1900 году секретарем Самарского губернского статистического комитета И.А. Протопоповым. Самара: Губ. тип., 1900. XXXIX, $520 \mathrm{c}$

62. Самарская газета от 24 августа 1903 г. № 163. 1903. 4 c.

63. Невоструев К.И. О городищах древнего Волжско-Болгарского и Казанского царств в нынешних губерниях Казанской, Симбирской, Самарской и Вятской. М.: Синодальная типография, 1871. 112 с.

64. Записка М.А. Миллера // Древности. Труды Императорского Московского археологического общества. Т. 22, вып. 1. М., 1909. С. 125-128.

Статья публикуется при поддержке гранта РФФИ в рамках научного проекта № 18-09-40115.

\title{
THE FIRST ATTEMPTS TO CREATE ARCHAEOLOGICAL MAPS OF SAMARA AND SIMBIRSK GOVERNORATES AT THE TURN OF THE XIX-XX CENTURIES
} (C) 2019

Sukhova Olesya Konstantinovna, master student of Domestic History and Archaeology Department Samara State University of Social Sciences and Education (Samara, Russian Federation)

Abstract. The paper discusses the experience of Russians and their attempt to create the first archaeological maps of Samara and Simbirsk Provinces, organized by V.N. Polivanov from Simbirsk and V.A. Miller and F.T. Yakovlev from Samara at the end of the XIX-XX centuries. The author introduces an archaeological map used by V.A. Miller and M.A. Miller into science. Due to the unpublished archival materials the author identifies the sources of information used to compile the archaeological map of the Simbirsk Province. For example, the use of a questionnaire describes the first steps in the centralized collection of information on ancient monuments in the Russian province in the $19^{\text {th }}$ century. The questionnaires of the Central Statistical Committee of 1873 and the Moscow Archaeological Society of 1888 are noted for solving the problem of creating archaeological maps of individual provinces. For example, the questionnaires of the Simbirsk provincial scientific archival commission of 1896 solved the map problem of the Simbirsk province. The time gap is considered between the creation of provincial scholars of archival commissions in Samara and Simbirsk, organizations that were not only in-charge of the preservation and processing of archival documents, but were involved in archaeological research and conducted activities to study antiquities. It is summarized that the Samara and Simbirsk provinces were at different levels of involvement in the all-Russian processes, but, one way or another, prerequisites were laid in both provinces for drawing up plans for further archaeological study of the two regions.

Keywords: questionnaire from 1873; questionnaire form 1888; archeology; archaeological map; V.A. Miller; M.A. Miller; questionnaires of 1896; V.N. Polivanov; provincial scientific archival commission; provincial statistical committee; questioning method; Moscow Archaeological Society; monuments of archeology; Samara province; Samara Museum; Samara Archaeological Society; Simbirsk province; F.T. Yakovlev.

$* * *$

УДК 94

DOI 10.24411/2309-4370-2019-14207

Статья поступила в редакцию 01.10.2019

\section{ПРОБЛЕМЫ СТАНОВЛЕНИЯ ЕПИСКОПАТА КИРИЛЛА АЛЕКСАНДРИЙСКОГО}

(C) 2019

Зайцева Ирина Валерьевна, кандидат исторических наук, старший преподаватель кафедры гуманитарных и социально-экономических дисциплин Белгородский юридический институт МВД России имени И.Д. Путилина (г. Белгород, Российская Федерациия)

Аннотация. В данной статье рассматриваются проблемы становления епископата одного из крупнейших деятелей Александрийской церкви Кирилла Александрийского. В работе представлены результаты проведенного анализа текстов «Церковных историй» Сократа Схоластика, Евсевия Кесарийского, Иоанна Никиусского, в которых обозначены ключевые вопросы формирования властных отношений в александрийском 
епископате IV-V вв. н.э. Проведенное исследование показало, что вступление Кирилла на епископскую кафедру было обусловлено практикой преемственности, сложившейся у александрийских церковных иерархов, начиная с Афанасия Александрийского, когда власть переходила по родовой линии от дяди к племяннику. Кирилл, получив епископскую кафедру «по наследству» от Феофила, столкнулся с рядом сложностей, требующих быстрого решения: борьба за кафедру с архидиаконом Феофила Тимофеем, продолжение практики «зачистки» никейского христианства от ересей, потребность в создании единой христианской интеллектуальной среды. Реализация этих задач стала возможной благодаря широкой поддержке общественных масс города, а также использованию Кириллом военной силы командующего императорскими войсками в Египте. В данной статье делается также акцент на развитии противостояния александрийского епископа с сектами новациан и крупной общиной иудеев.

Ключевые слова: Кирилл Александрийский; Александрия; ереси; Александрийская церковь; Феофил Александрийский; епископат; Сократ Схоластик; Евсевий Кесарийский; «Церковные истории»; Египет; префект Орест; Гипатия; Нитрия; «Долгие братья»; Эфесский собор; христологические споры; Новаций; новациане; мелитиане.

Кирилл Александрийский является одной из наиболее значимых фигур в истории церкви Египта IV-V вв. н.э. Его роль в формировании христианского интеллектуализма сложно переоценить, при том, что и до Кирилла церковь в Александрии знала немало выдающихся людей (Афанасий Александрийский, Дидим, Феофил и другие). Тем не менее именно с Кирилла начался переход от ортодоксального христианства к выраженному монофизитству, поскольку все епископы Александрийской церкви, стоявшие в ее главе после Кирилла, уже были монофизитами. В истории интеллектуальной мысли личность Кирилла в основном рассматривается через призму его теологических воззрений [1-7] и крайне мало обращается внимания на его выдающийся административный талант и высокие интеллектуальные способности. К числу наиболее важных с точки зрения анализа интеллектуализма Кирилла и его административной деятельности работ следует отнести труды таких авторов, как С. Вессел [8], Н. Рассел [9], Э. Артеми $[10 ; 11]$. В российской исторической науке труды подобной направленности отсутствуют, что отчасти актуализирует тему данной статьи. В этой связи основной целью работы выступает анализ наиболее проблемных сторон становления административной власти Кирилла Александрийского с опорой на интеллектуальный, а не теологический контекст его личности.

О раннем епископстве Кирилла источники в основном умалчивают. Церковные историки Сократ Схоластик и Иоанн Никиусский предоставляют нам единственные версии о раннем периоде становления епископата Кирилла. (После начала несторианской полемики источники крайне мало повествуют о епископстве Кирилла в Египте. - Прим. И.3.). Сократ сообщает, что Кирилл был избран епископом Александрии 17 октября 412 года в возрасте 34 лет. Это событие произошло через два дня после смерти его дяди Феофила, находившегося на посту руководителя Александрийской церкви с 385 года. Вступление Кирилла на епископскую кафедру было оспорено архидиаконом Феофила Тимофеем, который также претендовал на высокий церковный чин [12, 7.7]. Тимофея поддерживал александрийский префект Орест, что значительным образом осложняло позиции потенциального наследника, однако сам Кирилл пользовался широкой общественной поддержкой, что стало причиной к разрастанию конфликтной ситуации в городе. Сократ сообщает, что раздор между двумя партиями, соперничавшими за епископский пост, стал настолько серьезным, что Абунданций, командующий войсками в Египте, занимавший позицию, весьма схожую с позицией «rei militaris Aegypti», вмешался в процесс, встав на сторону Кирилла [8, p. 98-104]. (Дошедшие до нас греческие и сирийские рукописи свидетельствуют о том, что Тимофей, а не Кирилл получил военную поддержку от Абунданция. Однако когда переписчики, копировавшие греческие и сирийские рукописи, заменили Кирилла Тимофеем, измененный текст подразумевал, что военная поддержка, полученная Тимофеем, привела к избранию Кирилла епископом. - Прим. И.3.). Командующий войсками в Египте не подчинялся непосредственно императору, а находился под властью региональных магистратов (magistri) у которых сохранялась юрисдикция как над командующими (комитами), так и над генералами (дучами) [13, p. 100]. Это обстоятельство делало Абунданция достаточно свободным в выборе своих политических союзников.

Анализ более широкого повествования Сократа показывает, что его описание избрания Кирилла не вполне достоверно. Сократ был особенно обеспокоен тем, что Кирилл распространил свою власть за пределы традиционных церковных функций, связанных с епископской должностью, в частности на сферу светского управления, сосредоточив в своих руках большую власть, чем была у его предшественника Феофила $[12,7.7]$. Возможно, именно поэтому церковный историк приписывал позднейший конфликт Кирилла с императорским префектом Орестом презрению Ореста к таким епископам, как Кирилл, которые посягали на сферу политической власти, зарезервированную для императорских назначенцев [12, 7.13].

Эта критическая оценка распространения церковной власти Кирилла на политическую сферу была тесно связана с общим презрением Сократа к Кириллу $[14$, p. 16-17]. Подобное отношение было отчасти сформировано настороженным взглядом Сократа на спорящих епископов, которые угрожали нарушить мирное функционирование церкви. Сократ выразил эту точку зрения, изобразив Эфесский собор так негативно, что превратил длительные экуменические разбирательства в нечто большее, чем мелкий фракционный спор между двумя несогласными сторонами [12, 7.34].

На представление Сократа о Кирилле также повлияли его симпатии к общине новациан, раскольнической секте, названной в честь римского священника Новациана, который отказался принять христиан в лоно церкви после гонений императора Деция в 250 
гг. [15, p. 1-18]. Особенно беспокоило Сократа то обстоятельство, что Кирилл закрыл церкви новациан в Александрии вскоре после своего избрания на епископскую кафедру, не имея на то полномочий конкретного имперского законодательства. Утверждая, что эти действия против новациан не подпадают под надлежащее осуществление церковной власти, Сократ подразумевал, что секта утратила силу христиан, хотя они и не совершали церковного или богословского преступления. Позже Сократ предложил тот же аргумент против Целестина I, когда он закрыл церкви новациан в Риме [12, 7.11].

Новациане стали пользоваться терпимостью со стороны императорской власти за несколько лет до епископства Кирилла. В июне 383 г. Феодосий Великий провел в Константинополе Синод, на котором исследовал многочисленные еретические секты, чтобы продвигать церковные идеи единства и доктринального согласия между церквями Константинополя $[12,5.10]$. Каждого епископа, представляющего определенную еретическую секту, просили представить официальное заявление о принадлежности к ней. Сократ сообщает, что только новациане придерживались последовательных христологических верований, согласованных с Никейским вероучением, и представляли, таким образом, единственную еретическую группу, которой было разрешено собираться в пределах столицы империи [16, p. 49].

Почему Кирилл изменил политику веротерпимости своего дяди Феофила по отношению к новацианской общине, остается неясным. Возможно, это было важной частью более крупного церковного плана Кирилла по обеспечению своей власти над церквями Александрии и за ее пределами. Доказательства такого плана основаны на наблюдениях арабского церковного историка $\mathrm{X}$ века, который сообщает, что Кирилл сразу же после своего избрания назначил священников во всех церквях своей епархии. Тем самым Кирилл намеревался объединить александрийские церкви под своим руководством $[17$, p. 430]. Возможно, новациане, которые были известны как «чистые» за то, что отказывались принять в свою паству впавших в грех христиан, утверждали, что их моральный авторитет был выше, чем у церквей, находившихся под контролем Кирилла. По этой причине Кирилл закрыл их церкви и попытался интегрировать новациан в православие. Ряд авторов (например, А. Беленький) полагают, что причиной такого отношения со стороны Кирилла к новацианам стало то, что Савватий, Новацианский пресвитер в Константинополе, настаивал на обязательном праздновании Пасхи во время праздника пресного хлеба, т.е. поощрял празднование Пасхи в течение той же недели, что и еврейская Пасха, и поэтому поддерживал правильность еврейских вычислений весеннего равноденствия, открывая тем самым ящик Пандоры астрономических дебатов - область, в которой Кирилл чувствовал себя ниже светских астрономов [18, p. 389]. Новациане всегда праздновали Пасху в воскресенье, но с 387 года, после изменений в еврейском календаре, они начали праздновать ее на месяц раньше Александрийской церкви в два конкретных года, 8 и 19, в кругу 19-летнего александрийского пасхального цикла. Наказание, предписанное Феодосием I за празднование Пасхи в неподходящий день, было усилено в марте 413 года Феодосием II, специально издавшим указ, нацеленный на ущемление новациан. Ободренный последним указом, Кирилл уничтожил александрийских новацианов, так как он намеревался отпраздновать Пасху в 414 году в конце марта или апреле и боялся, что они отпразднуют Пасху 22 марта, в первый день Пасхи.

Ранее и Никейский Собор упрекнул мелитиан, ригористическую секту в Египте, которая также отказалась принять утративших силу христиан во время гонений 306 года, обнародовав шестой канон, в котором провозглашалось, что епископ Александрийский обладает властью над всеми церквами Египта [19, р. 28]. Эти действия предпринимались для того, чтобы устранить угрозу, которую мелитиане (возможно, как и Новаций) представляли для централизованной власти александрийского епископа, поскольку мелитиане претендовали на египетские церкви как на свои собственные. Как новоизбранный епископ Кирилл намеревался обеспечить более широкий имперский мандат над распространением раскольнических сект. Сократ утверждал, что Кирилл имел доступ к имперским войскам во время избирательного процесса. Подобная интерпретация событий вполне находится в духе повествования Сократа, который стремился изображать Кирилла как мирского епископа, действия которого против новациан были частью его политики по расширению своей церковной юрисдикции (Сократ был не первым церковным историком, который упрекнул Кирилла в попытке распространить свою власть на светскую юрисдикцию. Евсевий сообщает, что епископы низложили Павла Самосатского для учреждения трибунала внутри церкви [20, 7.30.9]. - Прим. И.3.). В этой связи необходимо быть осторожными с утверждением Сократа, что император поддерживал Кирилла и его последователей, предоставляя военную силу во время епископских выборов (избрание Кирилла в епископат действительно могло привести к насилию. - Прим. И.3.).

Сократ не дает точной и однозначной информации об отношении Кирилла к императорской власти. Вероятно, эти отношения Кирилла и светской власти в городе были гораздо более напряженными, чем пытался показать сам Сократ. Когда он писал об избрании Кирилла, то проиллюстрировал его конфликт с префектом Орестом [12, 7.13] и с императорским двором в первые годы несторианской полемики (Феодосий II отчитал Кирилла в начале несторианской полемики за то, что он предпринял попытку посеять раздор в императорской семье. Это было связано с тем, что Кирилл посылал отдельные трактаты императрицам, тем самым разжигая гнев императора. Прим. И.З.). Рассказ Сократа об избирательном процессе умалчивает о практических методах, которые использовал Кирилл, чтобы обеспечить победу над своим конкурентом Тимофеем. Хотя Сократ сообщает, что Абунданций собрал войска для того, чтобы обеспечить преимущество Кирилла, все же можно предполагать, что это могло быть и естественным, закономерным участием военных в вопросах, требующих силового разрешения. Следовательно, повествование Сократа не может объективно идентифицировать сторонников Кирилла в избирательном процессе или другие дополнительные средства, с помо- 
щью которых Кирилл мог бы ответить на спорный вопрос об обстоятельствах своего избрания. Вторым способом, который Кирилл использовал для достижения своих целей, стало вооружение нитрийских монахов [12, 7.7]. Так, Сократ сообщает, что Кирилл не колебался, используя монашескую силу в своем споре с префектом Орестом [12, 7.7].

Говоря о более широком спектре причин конфликта между Кириллом и Орестом, необходимо упомянуть ситуацию с крупной иудейской общиной, проживающей на территории Александрии. После вступления на епископскую кафедру Кирилл начал открытую политику против иудеев [18, p. 382]. Э. Уоттс указывает, что это могло быть связано с заботами Кирилла о религиозной среде города [21, p. 202]. Одним из его проектов как патриарха было создание интеллектуальной городской среды, в которой бы весомо звучали христианские аргументы против языческих. Основной причиной, по которой Кирилл изгнал иудеев из Александрии, по словам Coкрата, была их любовь к театральным зрелищам [18, p. 384]. (Перевод: Итак, в день субботний они [евреи] собираются большой толпой, так как евреи ничего не делают в этот день, даже не слушают их Закона, а проводят его в театральных забавах, то день стал для народа днем беспорядка. Хотя в какой-то степени это контролировалось Александрийским губернатором, тем не менее евреи противились этим мерам [12,

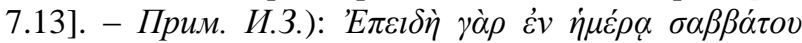

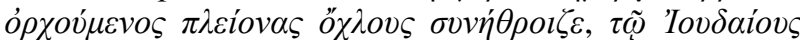

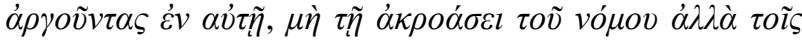

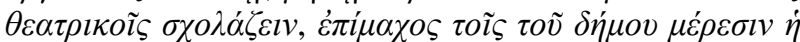
$\dot{\eta} \mu \varepsilon ́ \rho \alpha \kappa \alpha \tau \dot{\varepsilon} \sigma \tau$.

Пасхальная неделя в Александрии была выбрана танцорами как своего рода культурный фестиваль, о проведении которого распорядился префект Орест. Чтобы заработать деньги, они должны были выступать в еврейском квартале, расположенном в северовосточной части города (правда, в описании Сократом «субботнего дня» нет никаких конкретных подробностей о Пасхе. - Прим. И.З.). Однако танцы (или наблюдение за танцами) были бы совершенно неуместны для христиан на Пасху. Громкие аплодисменты танцоров и акробатов в Страстную пятницу и субботу, а также в Пасхальное воскресенье вызвали трения между еврейскими и христианскими общинами на всей территории еврейского квартала. Но тут произошло неожиданное событие, о котором сообщает Сократ $[12,7.13]$. Префект Орест ввел в практику оглашение собственных эдиктов в период проведения театральных представлений, на одном из которых присутствовали последователи епископа Кирилла [18, р. 384]. Среди них был некий Гиеракс (Иеракс), учитель литературы и восторженный слушатель проповедей епископа Кирилла, который привлекал к себе внимание частотой и громкостью аплодисментов. Евреи, которые увидели Гиеракса в театре, закричали, что он пришел туда только для того, чтобы провоцировать людей $\left(\delta l^{\prime} \quad\right.$ ov่ $\delta \dot{\varepsilon} v \quad \alpha \lambda \lambda o$

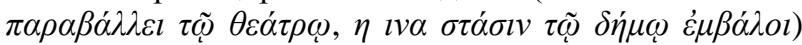
$[18$, p. 385]. А. Беленький отмечает, что эта причина выглядит вполне убедительной, поскольку Кириллу грозило противостояние с Римской церковью относительно датировки Пасхи и Гиеракс был выбран в качестве провокатора, чтобы прилюдно задавать евреям неудобные вопросы, касающиеся астрономии.
Орест занял позицию иудеев в этом вопросе и подверг Гиеракса прилюдным пыткам за его поведение [20]. (Сократ Схоластик сообщает, что поведение Ореста было вызвано завистью в отношении александрийских епископов, которые, по его мнению, претендовали не только на церковную, но и на светскую власть в городе $[12,7.13]$. - Прим. И.3.). Эта ситуация вызвала негодование у александрийского епископа, в результате чего он пригласил лидеров иудейской общины и потребовал перестать угрожать христианам. Сократ говорит, что еврейское население ( $\pi \lambda \circ o \tau \tau v v o o v \delta \alpha \omega \omega \nu)$, услышав об этих угрозах, вместо того чтобы подавить насилие, только еще более разъярилось и сговорилось уничтожить христиан. Один инцидент был особенно жестоким: согласившись с тем, что каждый из них должен надеть на палец кольцо из коры пальмовой ветви

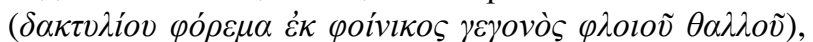
ради взаимного признания, они решили совершить ночное нападение на христиан [12, 7.13]. В одну из ночей иудеи подняли крик о том, что горит христианская церковь, освященная в честь Александра. Христиане, услышав это, выбегали на улицу, а евреи убивали их. Уже на рассвете виновники событий были установлены, что дало Кириллу возможность начать обратное наступление. Александрийский епископ в сопровождении толпы разгромил и разграбил еврейские синагоги, а еврейская община была изгнана из города 19 апреля 414 года [17, р. 388]. (Последующая история еврейского врача, которому удалось вернуться в Александрию только после обращения в христианство [12, 7.13], не оставляет сомнений в том, что все еврейское население было изгнано. - Прим. И.3.). Это событие подтверждает и Иоанн Никиусский.

Неожиданное изгнание евреев из Александрии стало отправной точкой для Ореста, чтобы начать расследование причин этого события. Согласно Сократу: Орест, префект Александрии, был очень возмущен этими событиями и чрезвычайно огорчен тем, что город такой величины внезапно лишился столь значительной части своего населения; поэтому он немедленно сообщил обо всем императору. Кирилл также писал [императору], описывая возмутительное поведение евреев, а между тем посылал людей к Оресту для посредничества в примирении. Когда Орест отверг попытки Кирилла примириться, последний протянул ему Библию, которую префект отверг. Поскольку Орест был христианином, его отказ мог означать только то, что Библия обладает сомнительным авторитетом, как, например, вопрос о начале весны» $[12,7.13]$. Вскоре префект сам стал жертвой насилия. Пятьсот монахов из Нитрийской пустыни пришли в Александрию и напали на Ореста, назвав его «язычником и греком» ( $\tau \eta v ~ к \alpha \lambda \lambda \lambda \eta v \alpha)$ и ранив его камнем $[12,7.14]$. Нападавшего, по имени Аммоний, Орест подверг наказанию, публично замучив до смерти. Вероятно, чтобы унизить Ореста, Кирилл приказал тело Аммония положить в одной из церквей, назвав его Фавмасием мучеником, принявшим благочестивую смерть. Подобные действия не были одобрены паствой, поскольку было очевидно, что Аммоний пострадал не за веру Христову.

А. Беленький отмечает, что Кирилл чувствовал угрозу еврейского сотрудничества с Римом. Но история еврейских отношений с Римской церковью не 
подтверждает этого предположения. Разделение Римской империи на две части в 395 году, несомненно, ослабило влияние Рима на Константинополь, оставив Александрийскую церковь единственным христианским остовом Восточной империи. Однако Кирилл за евреями чувствовал более грозную силу, которая шла от ариан и новациан. Вероятно поэтому, получив свой статус, Кирилл именно секту новацианов выбрал в качестве своего следующего удара.

Таким образом, первый период становления епископата Кирилла Александрийского сложно назвать легким. В противовес устоявшейся практике передачи епископской должности по родственной линии, Кириллу пришлось столкнуться со сложностями в установлении своей власти. Можем предположить, что границы, которые в этом вопросе устанавливали церковные историки, не отличаются избирательностью и объективностью, что обусловливает потребность в дальнейшей проработке данной темы.

\section{Список литературы:}

1. Boulnois M.-O. Le paradoxe trinitaire chez Cyrille d'Alexandrie. Herméneutique, analyses philosophiques et argumentation théologique. Paris: Institut d'Etudes Augustiniennes, 1994. 681 p.

2. Fernández Lois A.H.A. La cristologia en los commentarios a Isaias de Cirilo de Alexandria y Teodoreto de Ciro. Rome: Pontificia Universitas Lateranensis, Institutum Patristicum Augustinianum, 1998. 156 p.

3. Kearsley R. The impact of greek concepts of god on the christology of Cyril of Alexandria // Tyndale Bulletin. 1992. 43.2. P. 307-329.

4. Konrad F. Zawadzki Der Kommentar Cyrills von Alexandrien zum 2. Korintherbrief. Einleitung, kritischer Text, Übersetzung, Einzelanalyse // Traditio Exegetica Graeca 18. Leuven-Paris-Bristol, 2019. 444 p.

5. Konrad F. Zawadzki Der Kommentar Cyrills von Alexandrien zum 1. Korintherbrief. Einleitung, kritischer Text, Übersetzung, Einzelanalyse, Traditio Exegetica Graeca 16. Leuven-Paris-Bristol, CT, 2015. 615 p.

6. Konrad F. Zawadzki Keiner soll die Lektüre der Schrift durcheinanderbringen! Ein neues griechisches
Fragment aus dem Johanneskommentar des Cyrill von Alexandrien // Biblica. 2018. № 99. P. 393-413.

7. Konrad F. Zawadzki Syrische Fragmente des Kommentars Cyrills von Alexandrien zum 1. Korintherbrief, Zeitschrift für Antikes Christentum // Journal of Ancient Christianity. 2017. № 21. P. 304-360.

8. Wessel S. Socrates Narrative of Cyril of Alexandria's Episcopal Election // JTS. 52/1. 2001. P. 98-104.

9. Russell N. Cyril of Alexandria. London, Routledge, 2006. 272 p.

10. Artemi E. St Cyril of Alexandria and his relations with the ruler Orestes and the philosopher Hypatia // Ecclesiastic Faros of Alexandria. 2007. P. 7-15.

11. Artemi E. The use of the ancient Greek texts in Cyril's works // Poreia martyrias. 2010. P. 114-125.

12. Сократ Схоластик. Церковная история. М.: Росспэн, 1999. 400 с.

13. Jones A.H.M. The Later Roman Empire: 284602. Baltimore, 1964. 609 p.

14. Wessel S. Cyril of Alexandria and the Nestorian Controversy: The Making of a Saint and a Heretic. Oxford University Press, 2004. 365 p.

15. Gregory T.E. Novatianism: A Rigorist Sect in the Christian Roman Empire // Byzantine Studies / Études Byzantines. Vol. 2. 1975. P. 1-18.

16. Cyrille D'Alexandrie. Lettres festales / Ed. P. Évieux et al. Paris, 1991. 326 p.

17. History of the Patriarchs of the Coptic Church of Alexandria [El. resource] / Ed. B. Evetts. Pt. 2 // http://tertullian.org/fathers/severus_hermopolis_hist_ale x_patr_02_part2.htm.

18. Belenkiy A. The Novatian «Indifferent Canon» and Pascha in Alexandria in 414: Hypatia's Murder Case Reopened // Vigiliae christianae. 2016. Vol. 70. P. 373400.

19. Fonti P.P.J. Discipline Generale Antique (IVe IXe S.) Vol. 1.1 Les Canons Des Conciles Oecumeniques. Rome, 1962. 233 p.

20. Евсевий Кесарийский. Церковная история. М.: Амфора, 2007. $491 \mathrm{c}$.

21. Watts E.J. City and School in Late Antique Athens and Alexandria. Berkeley, Los Angeles, London: University of California Press, 2006. 302 p.

\title{
PROBLEMS IN THE DEVELOPMENT OF THE EPISCOPATE OF CYRIL OF ALEXANDRIA
} (C) 2019

\author{
Zaytseva Irina Valeryevna, candidate of historical sciences, \\ senior lecturer of Humanities and Social-Economic Sciences Department \\ Belgorod Law Institute of the Ministry of Internal Affairs of the Russian Federation named after I.D. Putilin \\ (Belgorod, Russian Federation)
}

Abstract. The paper deals with problems of the development of the Episcopate under one of the greatest person of the Alexandrian Church - Cyril of Alexandria. The paper analyzes the Historia Ecclesiastica by Socrates Scholasticus, the works of Eusebius Caesarea and John of Nikiu, that outlines the key issues of the establishment of power relations in the Alexandrian Episcopate in IV-V centuries. The research has shown that the Cyril's inauguration was prompted by the practice of continuity, which was developed in the Church Hierarchy, beginning with Athanasius of Alexandria, when power was handed down from uncle to nephew. After following his uncle Theophilus of Alexandria in a position by descent Cyril of Alexandria faced a number of important issues that needed quick response and significant resources: a power struggle with his rival Archdeacon Timotheus, continuing the practice of getting rid of heresy in the Nicene Christianity, and a need to establish a unified intellectual Christian environment. To solve these tasks was possible by a mass of public support as well as by using military force of the commander of the Emperor's troops. The paper also emphasizes an escalating confrontation between the Alexandrian Bishop, followers of Novatian and a large Jewish community.

Keywords: Cyril of Alexandria; Alexandria; heresies; Church of Alexandria; Theophilus of Alexandria; episcopate; Socrates Scholasticus; Eusebius of Caesarea; the Historia Ecclesiastica; Egypt; prefect Orestes; Hypatia; Nitria; Tall Brothers; Council of Ephesus; Christological controversies; Novatianus; Novatians; Meletians. 